\title{
ABORDAGENS DOS USUÁRIOS DA INFORMAÇÃO POR PROFISSIONAIS DA INFORMAÇÃO E DA INFORMÁTICA
}

\author{
INFORMATION USERS APPROACHES BY INFORMATION AND INFORMATION \\ TECHNOLOGY PROFESSIONALS
}

Eliane Cristina de Freitas Rocha

${ }^{1}$ Doutora em Ciência da Informação pela Universidade Federal de Minas Gerais (UFMG).

E-mail: prof.lili.rocha@gmail.com

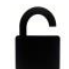

ACESSO ABERTO

Copyright: Esta obra está licenciada com uma Licença Creative Commons Atribuição 4.0 Internacional. $(\mathrm{cc}) \mathrm{Br}$

Conflito de interesses: A autora declara que não há conflito de interesses.

Financiamento: Não há.

Declaração de Disponibilidade dos dados: Todos os dados relevantes estão disponíveis neste artigo.

Recebido em: 17/04/2019.

Revisado em: 02/05/2019.

Aceito em: 09/05/2019.

\section{Como citar este artigo:}

ROCHA, Eliane Cristina de Freitas. Abordagens dos usuários da informação por profissionais da informação e da informática. Informação em Pauta, Fortaleza, v. 4, n. especial, p. 44-61, maio 2019. DOI: https://doi.org/10.32810/25253468.ip.v4iEspecial.2019.41036.44-61

\section{RESUMO}

Este artigo apresenta reflexões originadas e ampliadas de trabalho de tese realizado sobre as abordagens dos usuários da informação por profissionais da informação e da informática, sob orientação da professora Adriana Bogliolo Sirihal Duarte. Apresenta discussão sobre o conceito de usuário da informação, de sistemas de informação e de produtos interativos como categorias distintas. No que diz respeito ao trabalho dos profissionais da informação e da informática, há o predomínio da abordagem tradicional dos estudos de usuários na prática de ambos os perfis profissionais, marcada pelo empirismo e tecnicismo.

Palavras-chave: Usuário. Bibliotecário. Analista de tecnologia da informação. Usuário da informação. Usuário de sistemas de informação.

\section{ABSTRACT}

This paper presents reflections originated and amplified from a thesis accomplished about user information approacheb by information and information technology professionals, oriented by Adriana Bogliolo Sirihal Duarte. It presents discussion about information, information system and interactive products users as distinct cattegories. In concern of the work accomplished by information and information technology professionals, the tradicional approach of user studies dominates in the pratice of both professionals, characterized by empiricism and technicism.

Keywords: User. Librarian. Information Technology Analyst. Information User. System information user. 


\section{INTRODUÇÃO}

Este trabalho é fundamentado, essencialmente, em estudo de tese (ROCHA, 2013) orientado pela professora Adriana Bogliolo, a quem se presta homenagem nesta edição especial da "Informação em Pauta". Algumas reflexões posteriores à tese, publicadas em língua inglesa (ROCHA, 2016) e relacionados a ela são acrescentadas para permitir ao público brasileiro acesso às contribuições sobre os conceitos de usuários da informação em diferentes áreas do conhecimento - Biblioteconomia e Sistemas de Informação.

Na referida tese (ROCHA, 2013), ficou muito evidente que a temática dos usuários da informação tem recebido muita atenção no campo da ciência da informação, nos últimos anos. No entanto, o esforço teórico da área nem sempre é apropriado para melhoria nas atividades dos profissionais relacionados ao campo. Isso se deve, em parte: 1) à pluralidade temática e metodológica dos estudos da ciência da informação (CI), 2) à não correspondência entre os estudos do campo da CI e os espaços de atuação profissional alinhados ao desenvolvimento do seu campo científico: não existe uma profissão regulamentada de cientista da informação, e a definição de profissionais que podem atuar no campo é objeto de discussão. Para estabelecer um recorte necessário para compreender as abordagens dos usuários da informação em diferentes campos profissionais relacionados à $\mathrm{CI}$, a tese comparou a atuação de profissionais da informação (denominação da CBO/2002 aos profissionais bibliotecários) e profissionais da informática (analistas de tecnologia da informação) nos aspectos referentes às suas práticas relativas aos seus usuários.

Tendo em vista que González Teruel (2005) considera de fundamental importância que os estudos de usuários apresentem contribuições efetivas para a prática do profissional que lida com informação, a questão principal norteadora do trabalho foi: De que maneira têm sido abordados os usuários da informação nas práticas profissionais de bibliotecários e analistas de sistemas? O objetivo principal foi comparar as abordagens teórico-metodológicas dos usuários da informação nas práticas profissionais de bibliotecários e analistas de tecnologia da informação (profissionais da informática).

Para realizar tal empreitada, foi necessário realizar revisão bibliográfica das abordagens dos usuários da informação da CI, apresentada brevemente na seção 2 a seguir, que também apresenta reflexões sobre os conceitos de usuários da informação, 
usuários de sistemas de informação e de produtos interativos. Foi empreendido estudo de campo com profissionais 17 bibliotecários e 16 analistas de sistemas que lidam com usuários da informação, na tese. Reflexões originadas do trabalho empírico da tese serão apresentadas na seção 3. Para finalizar, são apresentadas considerações sobre as abordagens dos usuários da informação pelos profissionais.

\section{ABORDAGENS DOS USUÁRIOS DA INFORMAÇÃO}

Para González Teruel (2005), o histórico dos estudos de usuários aponta investigações de natureza heterogênea úteis ao planejamento de serviços de informação e voltadas para o estudo das necessidades da informação, estudo de demanda de informação, estudo de usos da informação, estudos de satisfação com os serviços informacionais, e estudos de impacto.

Os primeiros estudos de usuários voltaram-se para melhorias no desenvolvimento de coleções, sendo caracterizados como estudos de usos e de coleções das bibliotecas, empregando técnicas como análises estatísticas de empréstimo e uso da biblioteca, e bibliometria - como a avaliação do uso de periódicos, de referências, de citações (ARAÚJO, 2007). De acordo com Araújo (2007), os primeiros estudos de usuários da informação, das décadas de 1940 a 1980, conhecidos como estudos da abordagem tradicional, tinham orientação metodológica positivista, envolvendo a “aplicação dos métodos das ciências naturais (exatas e biológicas) aos fenômenos humanos ou sociais" (ARAÚJO, 2007, p. 87), com predomínio de técnicas quantitativas de pesquisa.

É característico dos estudos de usuários realizados na perspectiva positivistafuncionalista-empirista, normalmente associados aos primeiros trabalhos de estudos de usuários e ao paradigma físico da CI, o propósito de previsão do uso que indivíduos ou grupos fariam dos serviços de informação numa perspectiva voltada para a melhoria dos sistemas, sendo conhecidos como perspectiva orientada ao sistema (estudos orientados ao sistema) ou perspectiva tradicional dos estudos de usuários, associada ao seu valor pragmático no planejamento dos serviços de informação e melhoria/criação de bases de dados (GONZÁLEZ TERUEL, 2005).

Em meados da década de 1980, surgiram novas perspectivas de estudos dos usuários que deslocaram o foco do sistema para o entendimento dos usuários, 
desenvolveu-se "uma linha de investigação orientada ao usuário que atribuía ao usuário um papel ativo no processo de busca de informação, de tal maneira que o valor da informação dependia de sua própria percepção" (González Teruel, 2005, p. 55, grifos nossos, tradução livre), também conhecida como abordagem alternativa dos estudos de usuários. González Teruel (2005, p. 22) aponta que são característicos dessa abordagem o foco nas características "individuais, tanto cognitivas quanto afetivas que condicionam o modo com que se busca e utiliza a informação" e a observação das situações que levam o sujeito a necessitar da informação. Métodos qualitativos de pesquisa predominam nesta abordagem, alinhada ao paradigma cognitivo da CI (ARAÚJO, 2007). Alguns autores se destacam nesta abordagem: Khulthau, Brenda Dervin, Thomas Wilson, entre outros.

Araújo (2010), em sua revisão do campo, aponta que os estudos da abordagem tradicional (predominantemente marcados pelo paradigma físico da CI) e os estudos da abordagem alternativa (predominantemente marcados pelo paradigma cognitivo da $\mathrm{CI}$ ) não abarcam a complexidade da constituição da realidade social pelos sujeitos.

Talja (1997) sustenta que estudar o usuário de maneira individualizada conforme os moldes do paradigma cognitivo, e com uma visão de um sujeito orientado a fins racionais e práticos é abraçar o paradigma racionalista do processo de busca da informação, associado à dicotomia platônica que separa sujeito-objeto, a qual pressupõe, para Hjørland (1998) que a pessoa/usuário é provida de um pré-conhecimento que o permite interpretar os dados objetivos do mundo.

Talja (1997) acredita que seria necessário considerar os sujeitos como conhecedores, imersos em seus ambientes culturais (como em suas comunidades de prática), bem como considerar que a informação em si é construída socialmente. Ela propõe uma orientação diferente para os estudos de usuários - nem orientada ao sistema, nem orientada ao usuário - mas orientada para a formação de conhecimento (knowledge-formation orientation), a qual deveria dar conta, de um lado, tanto dos processos culturais de produção, organização e limites das necessidades de informação, quanto, de outro, da produção, limites e organização culturais dos sistemas de informação (TALJA, 1997, p. 77). A proposta envolve ampliar a compreensão do usuário da informação como um indivíduo que se comporta para um sujeito que realiza práticas culturais as quais, necessariamente, são informacionais. A abordagem oriunda desta 
visão não é tradicional, nem alternativa, mas social (ARAÚJO, 2010). Para abordar tais práticas, predominam técnicas qualitativas de pesquisa, e diversas abordagens teóricas do campo das ciências sociais são empregadas para empreender tais estudos.

Se os estudos de usuários envolvem estudos de "uso de bibliotecas ou de outros sistemas de informação", é preciso destacar que as mudanças tecnológicas trouxeram outras variáveis para os estudos de usuários. Baptista e Cunha $(2007$, p.176) incluem os estudos de usabilidade como voltados à "procura de soluções para sistemas de informação automatizados", o que permite identificar a problemática dos estudos de usuários em ambientes informatizados (como os ambientes informacionais digitais com a sua respectiva arquitetura da informação) como campo de interesse dos estudos de usuários.

Têm-se feito presentes, na CI, os estudos de usabilidade, acessibilidade e de comportamento informacional em contextos digitais, os quais se colocam, também, em abordagens (inter)(trans)(multi)disciplinares com outros campos do conhecimento, em especial com os estudos de caráter multidisciplinar da área de interação humanocomputador.

De maneira sumária, o campo de estudos de usuários relaciona-se com os paradigmas da Ciência da Informação em suas potencialidades e fraquezas e não é a ampliação dos contextos de investigação de estudo do campo (como o usuário em contextos digitais) em si portadora de novas abordagens teórico-metodológicas.

As formulações sobre o usuário da informação no campo da Ciência da Informação, no que diz respeito aos contextos digitais, interfaceiam e se apropriam de referenciais do campo da Interação Humano-Computador, o qual apresenta desenvolvimento próprio, também já avaliado como subproduto da tese que aqui se comenta (ROCHA; SIRIHAL DUARTE, 2013).

Os campos de estudo de usuários da Ciência da Informação e da Interação Humano-Computador atribuem aos usuários significados diferentes. Rocha (2016) considera que o usuário de produtos digitais interativos - inclusive dos produtos cotidianos como o tênis inteligente com informação embutida - não é o mesmo usuário de um livro. Primeiramente, não é adequada a expressão usuário de livro: Quem usa o livro é o leitor, o qual, mesmo em diferentes níveis de leitura (da mais ingênua à mais profunda), interage com uma obra aberta à sua interpretação. 0 livro pode também ganhar a forma digital - o e-book, o hipertexto - mas o sujeito que com ele interage 
entra em contato com saberes em diversos gêneros - romances, manuais técnicos - que hoje podem ter formato aberto, estar em constante construção por comunidades de usuários (na forma da escrita coletiva de enciclopédias online, por exemplo). A abertura à escrita e leitura coletiva de textos tem colocado o leitor no papel de produser - ao mesmo tempo usuário, leitor e produtor de registros de conhecimento (ZILLER; MOURA, 2010).

Na nova mídia (mídias digitais), o sujeito é convertido em usuário (MANOVICH, 2001) - o sujeito é essencialmente utilizador de recursos técnicos. O conhecimento da materialidade do livro impresso não se destaca na criação de um leitor, mas o conhecimento do recurso técnico em si (como os formatos dos livros eletrônicos, por exemplo) pode impedir várias operações de leitura/escrita/produção de registros de conhecimento em formato digital. Algumas ações de mediação explícita para auxílio à leitura podem se voltar, inclusive, para as dificuldades de uso dos aparelhos (ROCHA, 2013). Como se pode igualar o leitor de um livro com o usuário de um dispositivo eletrônico (como de um despertador eletrônico, por exemplo)? (ROCHA, 2016)

A comparação parece esdrúxula, mas constantemente nota-se que o usuário da informação, outrora associado ao leitor (àquele que produz, recupera e usa registros de conhecimento), é equiparado ao usuário de recursos técnicos digitais ou interativos. A terminologia usuário não tem o mesmo significado nos campos da biblioteconomia e da tecnologia da informação. Uma primeira e importante distinção diz respeito ao que seja usuário da informação, usuário de sistemas de recuperação da informação, usuário de sistemas de informação (em geral) e usuário de produtos interativos. Tais categorias encontram-se ilustradas na FIG. 1, com suas respectivas intersecções.

O usuário da informação é visto como o sujeito que manifesta comportamento informacional, entendido como as "atividades em que a pessoa se envolve quando identifica suas necessidades de informação, procura por tal informação por qualquer meio e usa ou transfere aquela informação"i (WILSON, 1999, p.249, tradução livre). Este usuário pode envolver-se em atividades de busca de informação (information seeking behavior) tanto ativa (active search, ongoing search) quanto passiva (passive atention, passive search), e também em atividades de recuperação da informação (information search behaviour) em sistemas de informação, conforme a proposição do modelo de comportamento informacional em camadas de Wilson (1999). Tais camadas são 
apresentadas na FIG.1 pelas elipses Usuário da Informação-Information Behaviour; Usuário da Informação-Information Seeking Behaviour e Usuário da InformaçãoInformation Searching Behaviour. O usuário é visto, predominantemente, de uma perspectiva subjetivista - alguém com necessidades de ordem psicológica, afetiva e cognitiva - como um sujeito que vai solucionar alguma questão relativa aos seus papeis nos contextos sociais (WILSON, 1999), como nos ambientes de trabalho, escolareseducativos e no cotidiano (campo da ELISii). Algumas das questões trazidas pelos usuários enfatizam a busca do conhecimento (necessidade da informação da ordem do saber, para Le Coadic, 2004 e que podem ser relativas aos contextos educativos/escolares bem como a situações cotidianas de troca de informação e diálogo entre pessoas apontadas por Savolainen, 2012) e, outras, a realização de tarefas de simples a complexas (SAVOLAINEN, 2012; LE COADIC, 2004), nas quais a necessidade de informação é derivada para realização de outra tarefa. Não se tem, aqui, exatamente, a visão do usuário como sujeito leitor ou como aquele que aprende com os recursos utilizados (ROCHA, 2016).

0 usuário da informação pode interagir com fontes de informação variadas tanto analógicas quanto digitais (pessoas, sistemas de recuperação da informação, por exemplo) em processos de busca ativa (active information seeking behaviour). Os usuários de sistemas de informação digitais são aqueles que utilizam aplicativos digitais de diversas naturezas - como os aplicativos de produtividade para o trabalho tanto pessoais (planilhas, editores de imagem, som, etc) quanto para empresas (sistemas ERP, por exemplo), incluindo os sistemas de recuperação da informação digitais (SRI) e sistemas de gestão de documentos (GED). Ao usar SRIs digitais, sistemas de informação digitais e produtos digitais em processos de recuperação da informação, o usuário apresenta information search behavior, mas pode também ser produtor de registros em repositórios digitais, numa aproximação à expressão produser (ROCHA, 2016).

O uso do sistema de informação digital se difere do uso de SRI também pela dinamicidade do tratamento dos dados armazenados: o sistema, para o usuário, é um meio para que ele acesse ou gere a informação que necessita de processamento de dados. A tarefa que o usuário realiza pode: a) envolver processos de busca ativa (active seeking) de algum item presente no sistema digital como um insumo informacional a ser recuperado para solucionar uma questão (como é o caso da recuperação da informação nos SRIs); b) precisar de insumo informacional processado ou gerado pelo sistema 
(necessidade da informação da ordem da ação, como nos sistemas de produtividade exemplo: usar sistema na realização de algum cálculo para fazer alguma previsão; ou necessidade da informação da ordem do saber, como um metereologista que consulta um modelo preditivo pluviométrico) para o qual o comportamento do usuário não se resume ao comportamento de busca, mas também à interação para geração de dados (uso interativo de sistema para processamento de dado); c) não ter como foco procura de informação ou geração de dados para solução de problemas (como em um sistema de entretenimento), mas envolver atividades informacionais relativas a processos de atenção passiva (passive attention - encontrar informação por acaso).

Outra maneira de abordar o usuário da informação, pela perspectiva do paradigma social construcionista, é vê-lo como um sujeito social imerso em comunidades de prática (SAVOLAINEN, 2007). O usuário da informação é aquele que realiza práticas informacionais (ao invés de manifestar comportamento informacional), entendidas como práticas sociais que incluem o trato com a informação em diversas dimensões - procurar, recuperar, receber, usar, transferir, indexar, etc - e por meio de variadas ferramentas que possibilitam comunicação e disseminação do conhecimento. 0 usuário da informação enquanto realizador de práticas informacionais, representado no círculo mais externo da FIG 1 (Sujeito Informacional), não é visto somente como um sujeito que lida com informação para solucionar alguma questão ou problema - ele realiza práticas sociais que são informacionais (como as práticas de diálogo com seus pares, por exemplo). Os ambientes nos quais são realizadas as práticas informacionais são relativos a contextos sociais com suas configurações próprias (atores e normas) que modelam a forma com que as trocas informacionais acontecem (information grounds), (COUTRIGHT, 2007).

Os usuários de produtos interativos, por outro lado, são aqueles que lidam com qualquer produto digital ou que tenha tecnologia digital embarcada para realizar tarefas cotidianas. 0 comportamento destes usuários de sistemas de informação digitais e produtos interativos nem sempre é associado à busca ativa de informação e não se enquadra completamente nos modelos que caracterizam o usuário em processos de atenção passiva e busca ativa (information behaviour). Este é o usuário de ferramentas digitais de uso cotidiano (aqui tratado como usuário interativo) para solucionar problemas da ordem do saber, da ordem da ação (a informação é subsidiária na 
realização de tarefas) no entendimento de LeCoadic (2004), ou da ordem da fruição, ou, simplesmente, para realizar práticas informacionais que tenham como suporte a tecnologia da informação digital.

A princípio, o uso de produtos interativos no cotidiano (como jogos eletrônicos, GPS, smart devices) pode ser visto como manifestação de práticas informacionais dos sujeitos, ou práticas sociais que envolvem fluxos informativos entre os sujeitos entre si e deles com os dispositivos técnicos. 0 foco do usuário, ao interagir com tais produtos, está no uso da ferramenta para realizar uma tarefa que envolverá ou não a busca de informação nas suas formas passiva ou ativa. Como exemplos têm-se: a) os usuários de um aplicativo como o Tinder têm como foco encontrar parceiros afetivo-sexuais (que é uma prática social) e, para isso, se envolverá em processos de busca ativa com a interface da ferramenta (active seeking); b) os usuários de uma casa inteligente (uma aplicação da computação ubíqua) que acende as luzes e executa uma música conforme o humor de seu morador, identificado pela leitura da retina, não realizam práticas informacionais nas formas de active searching, active scanning, non-directed monitoring ou by Proxy (associadas a práticas informacionais cotidanas por MCKENZIE, 2003). Em outras palavras, há um conjunto de produtos digitais interativos que recebem insumos informacionais dos seus usuários, os quais são tomados como objetos para a ação de tais produtos. No limite, tal objetificação traz à tona a discussão sobre se as práticas de uso de dispositivos digitais são sempre informacionais (se se considera que as práticas informacionais requerem consciência dos sujeitos) e se as aplicações das ferramentas digitais não se voltam para práticas que não sejam sociais (representadas além do sujeito informacional, no box mais externo da fig 1). 0 usuário de produtos digitais não necessariamente seria um usuário da informação (envolvido em processos de busca ativa ou passiva) nem um sujeito informacional (envolvido em práticas sociais informacionais).

Há, ainda, que se considerar a existência do usuário potencial de sistemas de recuperação da informação, de sistemas de informação digital e de produtos interativos: são todos aqueles que podem fazer uso de tais sistemas (público), mas não o fazem por diversas razões, como inadequação do seu habitus ao seu uso. Eles se diferem dos não usuários, os quais não se constituem no público-alvo de tais produtos, como é o caso dos analfabetos em bibliotecas especializadas, por exemplo. 
Figura 1 - Pessoas, sujeitos informacionais e usuários da informação

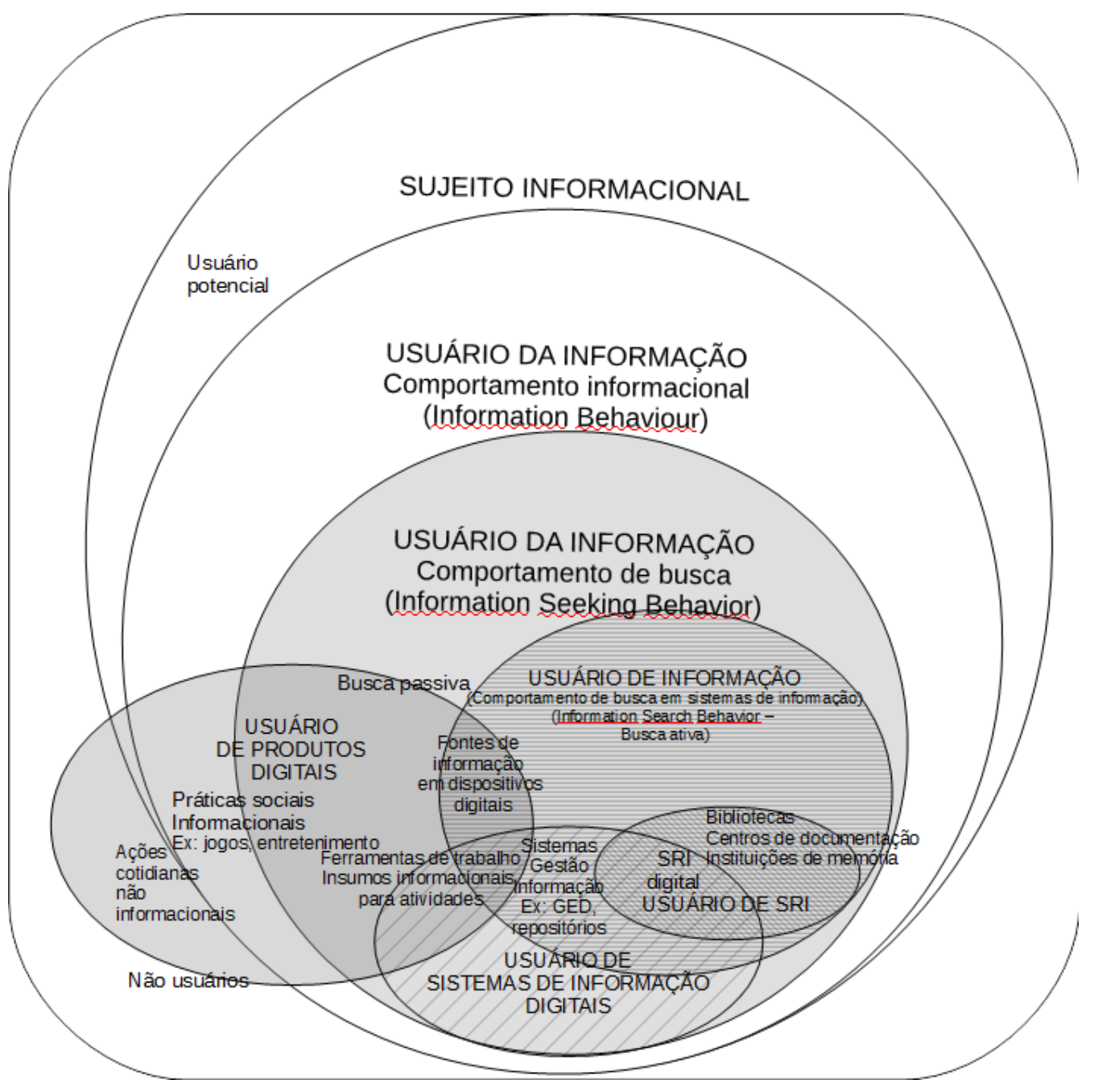

Fonte: elaborado pela autora.

Tendo em vista que há diferenças entre as abordagens teóricas das disciplinas de Usuários da Informação e Interação Humano-Computador, e os distintos conceitos relativos aos usuários da informação, as abordagens dos usuários pelos bibliotecários e analistas de tecnologia da informação foram comparadas tendo como parâmetro os referenciais das abordagens de usuários da CI (tradicional-orientada ao sistema; alternativa-orientada ao usuário e social-orientada à interação usuário-sistema).

\section{ABORDAGENS DOS USUÁRIOS PELOS PROFISSIONAIS}

Há duas grandes categorias de usuários de sistemas de informação (digitais ou analógicos) tratadas por duas grandes categorias de profissionais: 1) o usuário da 
informação, conforme visto pela de Biblioteconomia e Ciência da Informação e pelos profissionais bibliotecários; 2)o usuário de produtos digitais interativos (aqui tratado como usuário interativo) conforme visto pela área dos sistemas tecnológicos de informação, oriundos do campo da computação e congêneres.

O bibliotecário tem a responsabilidade de mediar a relação do usuário com os registros de conhecimento sob sua responsabilidade (ORTEGA Y GASSET, 2006). Para Almeida Júnior (2009) o trabalho de mediação tem duas dimensões: uma explícita, relativa ao atendimento e orientação do usuário, normalmente realizada pelo setor de referência; e outra implícita, relativa ao tratamento dos registros do conhecimento normalmente realizado pelo setor de processamento técnico. Com relação ao trabalho de mediação explícita, observa-se, no geral que: a) os bibliotecários de bibliotecas públicas e escolares se mostram atuantes nas ações de mediação explícita de ordem cultural (como a promoção da leitura), enquanto na biblioteca especializada tais ações não recebem tanta atenção quanto a disseminação seletiva, por exemplo; b) nas bibliotecas universitárias e também nas escolares, tem grande relevo as ações de letramento informacional e digital (auxílio ao usuário na localização de fontes, no uso de equipamentos digitais e normas bibliográficas, na elaboração de trabalhos escolares).

Já com relação ao trabalho do analista de tecnologia da informação, nota-se que há diferentes perfis profissionais a lidar com usuários conforme a divisão das tarefas existente no mercado da tecnologia da informação. Os processos de trabalho dos analistas mais diretamente associados aos usuários de sistemas estão associados, no ciclo de desenvolvimento de sistemas, às etapas de análise de requisitos, implantação e operação de sistemas (NASCIMENTO, 2003); e, no ciclo do design centrado no usuário, às etapas de identificação das necessidades dos usuários e suas tarefas (parte da investigação contextual) e à avaliação do design (ROCHA, 2013). Há diferentes papeis profissionais que lidam com os usuários de sistemas de informação e produtos interativos: os que realizam trabalho de mediação implícita - elaboram projetos de produtos interativos para os seus potenciais usuários - e aqueles que realizam trabalho de mediação explícita - auxílio dos usuários no uso de produtos. De maneira sumária, o trabalho de mediação explícita é realizado por analistas de TI que têm a função de analistas de suporte (e analistas de negócio), os quais teriam a função de facilitar o uso dos sistemas e mediar modificações nele junto às equipes de analistas-desenvolvedores. As tarefas de conhecer as necessidades de usuários para elaboração de sistemas digitais 
(software) e produtos interativos - tarefas de mediação implícita - são divididas em dois perfis profissionais, basicamente: a) os designers de interação ou UX designers (User Experience Designers) são responsáveis por projetar as interações dos usuários com produtos interativos de qualquer natureza (desde interfaces de softwares para computadores desktop e interações humanas com dispositivos inteligentes e ambientes com computação ubíqua) e podem atuar em conjunto com arquitetos da informação (estes são responsáveis pela estrutura de navegação, rotulação, organização e busca da informação em variados ambientes digitais); b) os analistas de sistemas ou engenheiros de software são responsáveis pelos produtos de software (desde sua concepção, desenvolvimento e gestão), podendo existir subdivisões desta especialidade conforme o porte e a estrutura da empresa empregadora, como é o caso do perfil profissional específico do analista de requisitos computacionais (responsável pela concepção das soluções).

Além dos profissionais de TI, há outros papeis de mediação, como redação técnica, e acompanhamento de clientes por equipe de marketing (que também prospecta necessidades de usuários e propõe novas funcionalidades ou produtos) e consultores externos (como consultores da área de negócios), atuando no mercado da tecnologia da informação que lidam com usuários da tecnologia digital.

\subsection{Abordagens pelos profissionais da informação}

Em Rocha (2013), nota-se que, nas atividades de trabalho realizadas pelos bibliotecários, o usuário é visto como o usuário da informação envolvido em busca de informação para solucionar essencialmente problemas de ordem das necessidades do saber (por exemplo: como fazer uma monografia, armazenar ou recuperar um documento). Quando este usuário utiliza os SRIs (no acervo das bibliotecas, nas bibliotecas digitais, nos repositórios institucionais, nos sistemas de gestão de documentos), ele também é usuário de sistemas de recuperação da informação e apresenta comportamento de procura de informação (information search behavior) mas também pode ser produtor de documentos (como no caso dos sistemas de Gestão Eletrônica de Documentos, ou no caso dos repositórios de objetos digitais, como os repositórios de objetos de aprendizagem). Tal visão majoritária - o usuário como aquele 
que procura informação para conhecer ou saber de algo - é relacionada ao paradigma tradicional dos estudos de usuários (system-oriented approach, perspectiva tradicional, centrada no sistema) (TALJA, 1997): o usuário é o sujeito racional à busca da informação para solução dos seus problemas que requerem ações de mediação do bibliotecário relativas à busca da informação, e que exige dele conhecimento acerca dos conteúdos pesquisados e de seus formatos. 0 papel de mediação do profissional bibliotecário, neste caso, está relacionado à facilitação do acesso às fontes de informação e boa gestão do acervo, e à promoção do letramento digital e informacional, o qual requer, em muitos momentos, ações culturais (como as de promoção da leitura). 0 usuário é alguém a quem se deve dar atenção, é um sujeito apressado interessado em recuperar registros de informação e também em armazená-los, mas que nem sempre está preparado para realizar tais operações (não sabe ler tão bem, não conhece tão bem a natureza das fontes).

O usuário da informação presente na fala dos bibliotecários entrevistados na tese pode ser entendido como aquele que está à procura de um insumo informacional para solucionar alguma questão, seja na biblioteca, em SRIs, em sistemas de informação (digitais ou não), ou de fontes como meios de comunicação e pessoas. A problematização acerca dos não-usuários, ou dos usuários com necessidades não expressas é tímida entre os profissionais bibliotecários (ROCHA, 2013).

O comportamento informacional (information behaviour) não se mostrou objeto de atenção dos profissionais bibliotecários. Tampouco se vê presente a problematização do sujeito informacional - o sujeito imerso em práticas sociais relativas à informação. Valem as impressões do cotidiano para conhecer o usuário. Os usuários, nestas impressões, são vistos como apressados, sem paciência, e pragmáticos: precisam realizar alguma tarefa de recuperação da informação e criação de conhecimento. Mas ele também é visto na faceta de leitor, como alguém a quem se deve instruir e educar.

Para os sistemas digitais, porém, os bibliotecários atuantes em repositórios digitais não têm uma ideia muito precisa de quem é o usuário, especialmente por ele não estar fisicamente presente no espaço da biblioteca. Nestes espaços também é um desafio lidar com o produser, como se notou no caso de dificuldades de auxílio a produtores de objetos digitais de aprendizagem em um repositório digital, e também se nota atuação no sentido de melhoria da findability de tais ambientes. 
De maneira geral, predomina a falta de sistematização do conhecimento do usuário pelos bibliotecários entrevistados na tese (ROCHA, 2013), predominando abordagem tradicional na forma se compreender quem é o usuário. As impressões da experiência direta, empírica, e as abordagens técnicas e práticas predominam para entender o usuário, em uma perspectiva orientada ao sistema.

\subsection{Abordagens pelos profissionais da informática}

Do ponto de vista do analista de TI, o usuário é, prioritariamente, um executor de processos de trabalho ou de tarefas cotidianas que envolvem fluxos informacionais. $\mathrm{Na}$ fala dos analistas de TI (ROCHA, 2013), há distinção entre os sistemas de produtividade (como os sistemas ERP, planilhas eletrônicas, etc), feitos para usuários trabalhadores, e os aplicativos/sistemas sociais voltados para um amplo mercado (como os jogos, com finalidade de entretenimento), feitos para o público (público consumidor). Tal distinção guarda analogias com a especificidade dos estudos de usuários em ambientes de trabalho (workplace) e nos ambientes cotidianos (everyday life seeking) que já se manifesta no campo da HIB (MACKENZIE, 2003; COURTRIGHT, 2007; SAVOLAINEN, 2012).

$\mathrm{O}$ analista de TI, para desenvolver produtos interativos voltados a quaisquer dos perfis de usuários e características dos sistemas, precisa mapear fluxos de informação e definir modelos de dados e sua manipulação. Ele cria uma representação do mundo social e concebe um sistema dinâmico que processa dados de entrada e gera saídas/resultados.

Na prática dos profissionais analistas de TI que não são designers de interação (como os analistas de suporte, analistas de sistemas, engenheiros de software), o usuário é um gerador de problemas, solicitante de serviços, entendedor do domínio de trabalho que precisa ser consultado. Os levantamentos de requisitos de sistemas realizados junto a usuários - como os realizados por analistas de sistemas e de requisitos, bem como por alguns bibliotecários na elaboração de SRIs [Sistemas de Recuperação de Informação] - envolvem realização de pesquisas de necessidades informacionais de usuários. Neste caso, as técnicas utilizadas são qualitativas - como entrevistas e estudo de documentação dos sistemas existentes ou do domínio. 0 usuário 
pode ser visto em seu comportamento informacional, como aquele envolvido em processos de procura de insumos informacionais tanto em SRIs (information search behavior) quanto em sistemas digitais ou aquele envolvido em processos de busca (information seeking behavior) tanto ativa quanto passiva.

O usuário de sistemas de informação digitais (que pode ser usuário envolvido em busca ativa de informação) requer do analista de TI, em suas funções de suporte e análise de negócios, não exatamente o domínio do saber associado às tarefas dos usuários (trabalho do catalogador), mas a forma com que as tarefas do usuário são realizadas e suas restrições (as regras do processamento e transformação dos dados, as regras de negócio). 0 trabalho de mediação explícita do analista não se restringe ao auxílio na recuperação de dados estáticos. Não se pode dizer que o analista de TI promova o letramento informacional, nem que ele esteja tão atento ao letramento digital na sua dimensão técnica. Do ponto de vista do analista de TI, de maneira geral, muitos problemas associados aos usos dos sistemas são problemas de projeto e não de falta de preparo do usuário.

Por outro lado, a concepção de produtos interativos requer equipes multidisciplinares que contam com o designer de interação, o qual não tem como atribuição definir modelos de dados para os sistemas. 0 projeto de tais produtos está mais ligado às ações/tarefas exercidas pelos usuários no cotidiano que podem ou não ter a informação como subsidiária à sua realização. 0 usuário de tais produtos muitas vezes é visto como o público com necessidades de ordem social a serem exploradas pelo mercado dos produtos interativos, por exemplo: quais são as features mais atrativas para os celulares (como a criação do pau de selfie para as fotos)? Só se projeta um pau de selfie quando se observa o comportamento social e não os insumos informacionais ofertados pelos aparelhos de celulares e seus usos (seus metadados). 0 usuário é um usuário do produto, a exercer tarefas cujo foco não está na visão de obtenção da informação para suprir uma lacuna. O comportamento dos usuários nos ambientes digitais pode ser qualificado ou quantificado por meio de testes, como aqueles que empregam análises métricas (análise de page views em websites, por exemplo). 0 usuário de produtos interativos não é necessariamente um usuário de informação que expressa comportamento informacional, embora possa (e deva) ser visto como um sujeito informacional. 
No sentido de criar produtos interativos, os designers de interação e UX designers adotam um conjunto de técnicas empíricas que envolvem o conhecimento dos usuários em seu cotidiano, o conhecimento do modelo de negócio (propósitos comerciais) e as restrições da tecnologia envolvida (ROCHA, 2013). Normalmente as técnicas utilizadas são qualitativas - uso da etnografia rápida, observação do ambiente de trabalho, entrevista semi-estruturada, grupos focais. Interessa saber qual é o ponto de vista do usuário sobre as funcionalidades ou produtos que serão criados, a pesquisa tem um caráter prospectivo. 0 trabalho visa conhecer as práticas sociais para que sejam criadas soluções (na forma de protótipos) que são testados pelos usuários (testes de usabilidade) ou pelas equipes de trabalho (inspeções de usabilidade) para serem produzidos comercialmente.

Embora os usuários participem da prospecção de ideias e validação de protótipos e sejam informantes para geração de sistemas e solução de problemas, não se notou participação efetiva dos usuários nos processos de concepção dos sistemas, experiências de cocriação de produtos interativos (ROCHA, 2013). A eficiência e a eficácia dos produtos e sistemas são critérios de qualidade para concepção de produtos: o usuário é um sujeito pragmático que quer realizar tarefas cotidianas de maneira mais prática, independentemente dele ser visto como público consumidor de produtos interativos (que podem ser ubíquos) ou como trabalhadores usando ferramentas de produtividade. Ele também é visto em uma relação utilitarista: ele é um elemento de cálculo para o sucesso de um produto, de um sistema e não é tido como um sujeito autônomo ou produtor de conhecimento. Nesta direção, predomina a abordagem empirista, orientada ao sistema, típica da primeira orientação de estudos de usuários da CI (abordagem tradicional).

\section{CONSIDERAÇÕES FINAIS}

Os bibliotecários lidam com usuários que buscam conhecimento, enquanto os analistas de TI com trabalhadores e público consumidor de produtos interativos. De maneira geral, há afastamento no propósito nas ações de mediação dos profissionais - o bibliotecário auxilia a busca do conhecimento do seu usuário (leitor, trabalhador em busca de insumos informacionais), já o analista de TI projeta ferramentas para 
realização de alguma atividade cotidiana de maneira mais eficiente (trabalhador, público consumidor) e, eventualmente, dá suporte ao seu uso.

A visão predominante do usuário por ambos os perfis profissionais é orientada ao sistema. Do ponto de vista do analista de TI, é preciso conhecer o seu usuário para cativá-lo, o que torna necessário o conhecimento de suas práticas sociais para esclarecimento dos fluxos informacionais (práticas informacionais) na proposição de produtos para os sujeitos-objetos de ações mercadológicas. Do ponto de vista do bibliotecário, seria importante compreender os usuários em suas práticas sociais para entender o valor da informação na cultura a fim de evitar que o sujeito informacional seja subsumido ao consumidor de produtos interativos.

\section{REFERÊNCIAS}

ALMEIDA JÚNIOR, Oswaldo Francisco de. Mediação da informação e múltiplas linguagens. Pesq. bras. Ci. Inf., Brasília, v.2, n.1, p.89-103, jan./dez. 2009.

ARAÚJO, Carlos Alberto Ávila. Estudos de usuários: uma abordagem na linha ICS. In: REIS, A. S; CABRAL, A. M. R. (Org.).

Informação, Cultura e Sociedade: interlocuções e perspectivas. Belo Horizonte: Novatus, 2007. p. 81-100.

ARAÚJO, Carlos Alberto Ávila. Estudos de usuários conforme o paradigma social da ciência da informação: desafios teóricos e práticos de pesquisa. Informação \& Informação, Londrina, v. 15, n. 2, p. 23-39, jul./dez. 2010.

COURTRIGHT, Christina. Context in Information Behavior Research. Annual Review of Information Science and Technology, v. 41, p. 273-306, 2007.

HJøRLAND, B. Theory and metatheory of information science: a new interpretation. Journal of Documentation, v.54, n.5, p. 606621, 1998.

BAPTISTA, Sofia Galvão; CUNHA, Murilo Bastos da. Estudo de usuários: visão global dos métodos de coleta de dados. Perspectivas em Ciência da Informação,
Belo Horizonte, v. 12, n.2, p. 168-184, maio/ago./2007.

GONZÁLEZ TERUEL, Aurora. Los estudios de necessidades y usos de la información: fundamentos y perspectivas actuales. Ediciones Trea S. L., 2005.

LE COADIC, Yves-François. A ciência da informação. 2 ed. rev. e atual. Brasília: Briquet de Lemos, 2004.

MANOVICH, Lev. The language of new media. Massachusetts: MIT Press, 2001.

MCKENZIE, P.J. A model of information practices in accounts of everyday-life information seeking. Journal of Documentation, v. 59, n.1, pp. 19-40, 2003.

NASCIMENTO, Luciano Prado Reis. 0 usuário e o desenvolvimento de sistemas. Florianópolis: Visual Books, 2003. Cap. 1/3.

ORTEGA Y GASSET, José. Missão do bibliotecário (1935). Brasília, DF: Briquet de Lemos, 2006.

ROCHA, E. C. F. Usuário da informação, um velho (?) (des)conhecido: usuários da informação em diferentes profissões da informação. 2013. 364 f. Tese (Doutorado em Ciência da Informação) - Universidade 
Federal de Minas Gerais, Belo Horizonte, 2013.

ROCHA, E. C. F.; SIRIHAL DUARTE, A. B. Reflexões sobre os paradigmas de estudo da usabilidade na Ciência da Informação.

Datagramazero (Rio de Janeiro), v. 14, p. 01-11, 2013.

ROCHA, E. C. F.. Information Users X Interactive Users: Different Subjects Challenging Different Information Professionals. Annual International Conference on Library and Information Science, 2., 2016, Atenas. ATINER'S Conference Paper Series. Atenas: Athens Institute for Education and Research, 2016.

SAVOLAINEN, R. Information Behavior and Information Practice: Reviewing the "Umbrella Concepts" of Information-Seeking Studies. Library Quarterly, v.77, n.2, p 109132. 2007.

SAVOLAINEN, R. Conceptualizing information need in context. Information
Research, v.17, n.4., 2012. Disponível em: http://InformationR.net/ir/174/paper534.html.

TALJA, Sanna. Constituting "information" and "user" as research objects: a theory of knowledge formations as an alternative to the information man - theory. In: VAKKARI, P.; SAVOLAINEN, R.; DERVIN, B (Ed). Information seeking in context. Taylor Graham Publishing, London, UK, 1997.

WILSON, T. D.. Models in information behaviour research, Journal of

Documentation, v. 55, n 3, pp. $249-270$. 1999.

ZILLER, Joana; MOURA, Maria Aparecida. Semiose e fluxos informacionais: os agenciamentos coletivos e a condição de usuário em ambientes digitais. Liinc em Revista, Rio de Janeiro, v.6, n.2, p. 324-340, set. 2010.

\footnotetext{
$\mathrm{i}$ “activities a person may engage in when identifying his or her own needs for information, searching for such information in any way, and using or transferring that information".

ii Everyday Life Information Seeking.
} 